\title{
The densification of layered polar firn
}

\author{
M. W. Hörhold, ${ }^{1}$ S. Kipfstuhl, ${ }^{1}$ F. Wilhelms, ${ }^{1}$ J. Freitag, ${ }^{1}$ and A. Frenzel ${ }^{1}$ \\ Received 10 December 2009; revised 7 October 2010; accepted 28 October 2010; published 4 January 2011.
}

[1] High-resolution density profiles of 16 firn cores from Greenland and Antarctica are investigated in order to improve our understanding of the densification of layered polar firn. A vertical resolution of 1-5 mm enables us to study the detailed densification processes and the evolution of the layering and the resulting variability in density with increasing depth. The densification of layered firn is important for the process of air enclosure in ice and is connected with the observed formation of a nondiffusive zone. Our findings show the following. (1) Mean density profiles, obtained from high-resolution measurements, only partly show clear transitions in densification rate at densities of 550, 730 , or $820-840 \mathrm{~kg} / \mathrm{m}^{3}$, as they are commonly used in literature. (2) The density variability, induced by the layering, shows a similar pattern at all sites: high variabilities at the surface, a rapid drop to a relative minimum in variability at mean density of $600-650 \mathrm{~kg} / \mathrm{m}^{3}$, followed by a second relative maximum. (3) This leads to increased variability at densities of the firn-ice transition for most of the sites. (4) The variability at the surface decreases with increasing mean annual temperature and accumulation rate, whereas the variability at the firn-ice transition increases. We can exclude a change in local climate conditions as an explanation for the density variability since the firn cores in this study cover a broad range in mean annual temperature, accumulation rate, and age. Overall, high-resolution density profiles deliver a more complex picture of compaction of polar firn as a layered granular medium than has been obtained from mean density profiles in the past.

Citation: Hörhold, M. W., S. Kipfstuhl, F. Wilhelms, J. Freitag, and A. Frenzel (2011), The densification of layered polar firn, J. Geophys. Res., 116, F01001, doi:10.1029/2009JF001630.

\section{Introduction}

[2] Density, as a physical property of polar firn, is important not only as a material characteristic, but for many topics of polar research. This includes the monitoring and modeling of ice sheet mass balance, by means of ground penetrating radar or satellite laser altimetry [Li and Zwally, 2002, 2004; Rott et al., 1993; Rotschky et al., 2006], and the enclosure of air bubbles in the ice during the transformation from snow to ice [Martinerie et al., 1992; Schwander et al., 1997].

[3] Different densification processes, acting at certain depth intervals of the firn column, have been investigated and discussed by others [Anderson and Benson, 1962; Alley et al., 1982; Maeno and Ebinuma, 1983; Alley, 1987; Ebinuma and Maeno, 1987; Paterson, 1994; Arnaud et al., 1998; Salamatin et al., 2009]. Mean "critical" density values of 550, 730 and $820-840 \mathrm{~kg} / \mathrm{m}^{3}$ are often denoted for changes in the predominance of microscale processes. Examples are particle rearrangement [Gow, 1974; Herron and Langway, 1980; Ebinuma and Maeno, 1987; Paterson, 1994; Salamatin et al., 2009], grain boundary sliding, recrystallization, creep [Maeno and Ebinuma, 1983; Ebinuma and Maeno, 1987] and air

\footnotetext{
${ }^{1}$ Alfred Wegener Institute for Polar and Marine Research, Bremerhaven, Germany.

Copyright 2011 by the American Geophysical Union. 0148-0227/11/2009JF001630
}

bubble shrinking [Gow, 1974; Martinerie et al., 1992]. Yet there are hints that these critical densities vary considerably for different snow and firn types [Alley et al., 1982; Johnson, 1998; Freitag et al., 2004]. Deformation and grain boundary sliding seem to occur concurrently from the very beginning of compaction [Arnaud et al., 2000], and grain boundaries in microstructure images show signatures of dynamic recrystallization in shape, orientation and number rather than structures resulting from normal grain growth [Kipfstuhl et al., 2009]. Models of firn densification usually consider a mean density profile [Herron and Langway, 1980; Barnola et al., 1991; Arnaud et al., 1998, 2000; Goujon et al., 2003]. The evolution of density with depth is often linked to mean annual air temperature, accumulation rate and surface density [Herron and Langway, 1980; Maeno and Ebinuma, 1983; Martinerie et al., 1992], overburden pressure [Kameda et al., 1994] or surface winds [Craven and Allison, 1998].

[4] Polar firn is a highly layered medium and thus exhibits heterogenous material properties [Gow, 1974; Hansen and Brown, 1986]. Stratigraphy is created by seasonal changes of the local climatic conditions. At high-accumulation sites the stratigraphy is made by layers from single snow fall or drift events, while at low-accumulation sites most likely only summer and winter precipitation create stratigraphy. Layers can be distinguished not only by their bulk density but also by grain size and shape, hardness, viscosity and coordination number. Accordingly, variability in such different properties 
will lead to different response to pressure loads [Palais et al., 1982; Hansen and Brown, 1986; Johnson, 1998; Alley et al., 1982].

[5] Furthermore, the increase in density seems to vary not only within the firn layers but also with time. Zwally and $L i$ [2002] observe seasonal variations in ice sheet elevation and link these to variable densification rates through the year. The variability in densification is caused by seasonally changing temperatures and accumulation rates. Their models show that the amplitude of density variability increases with the accumulation rate, whereas the frequency decreases with increasing accumulation rate. This variability vanishes with depth [Li and Zwally, 2004].

[6] The layering and the related variability in density is an important factor when discussing the age difference between air enclosed in bubbles and the surrounding ice. As long as the pores are connected with the surface, an exchange with the atmosphere by diffusion is possible. The depth, and thus age, when pore close-off is expected, is often derived using mean density critical values [Martinerie et al., 1992; Schwander et al., 1997]. However, considering layering, and thus density variability, consequently leads to depth intervals where some layers have already reached the pore close-off density. Other layers still show connected pores. This depth interval is often referred to a nondiffusive zone, where air can escape upward but no downward air exchange is possible. It is common to interpret the high-density layers, which approach the pore close-off density first, as the initially high-density layers originating at the surface (often referred to winter precipitation) [Martinerie et al., 1992; Severinghaus and Battle, 2006].

[7] Recently, the degree of layering has been considered as a parameter influencing the extent of the nondiffusive zone. Landais et al. [2006] suggest that strong layering, as is expected for high-accumulation sites, results in the existence of a nondiffusive zone. At low-accumulation sites, the layering vanishes at the surface and a nondiffusive zone is not expected. Also, Kawamura et al. [2006] suggest that the thickness of the nondiffusive zone generally depends on the amplitude of density variability due to the layering at the surface and the horizontal extent of single layers, typically generated by seasonal variations of deposited snow density.

[8] Density variability generated by layering can be investigated by using high-resolution density measurements. We use the term high-resolution to refer to a vertical resolution of 1 to $5 \mathrm{~mm}$ with depth, which is much higher than the typical $1 \mathrm{~m}$ averages. This resolution is small compared to the thickness of single layers, which is usually found to be in the range of several $\mathrm{cm}$. High-resolution density measurements of polar firn were published by Gerland et al. [1999] for the B25 core from Berkner Island, Antarctica, and by Freitag et al. [2004] from site B26, Greenland. Both observed that the variability decreases rapidly in the upper 20-30 m. Below, the variability increases again, yielding a second relative maximum. Gerland et al. [1999] also found a negative correlation between density and electrical conductivity measurements (ECM) in the upper firn column, which changed at $30 \mathrm{~m}$ depth to a positive correlation. Hawley and Morris [2006] published high-resolution profiles of borehole density logging techniques and optical stratigraphy at Summit, Greenland. They find a positive correlation between optical brightness reflections and density, which decreases with depth and turns to a negative correlation between 20 and $25 \mathrm{~m}$ depth.

[9] Gerland et al. [1999] and Freitag et al. [2004] explained the second relative maximum in density variability by the more efficient densification of coarse grained, initially low-density firn, compared to fine grained, initially highdensity firn. This would lead to a crossover in the density profiles. The depth at which the densities of coarse and fine grained firn are approximately equal is associated with the minimum in density variability. This observation indicates that below the variability minimum, the initially low-density firn layers show higher densities than the initially highdensity firn layers, which would explain the switch in the ECM-density correlation. Other authors considered this second maximum in density variability as a singular abnormal finding, possibly due to interannual changes in weather conditions [Li and Zwally, 2002]. Hawley and Morris [2006] explain the change from positive to negative correlation between density and brightness by the transition from grain boundary sliding to pressure sintering as the dominant firn densification mechanism. Recently, discontinuous highresolution profiles of density and crystal orientation of a firn core from Dome Fuji were published [Fujita et al., 2009] showing a switch from positive to negative correlation between density maxima and structural anisotropy at $30 \mathrm{~m}$ depth, supporting the ideas of Gerland et al. [1999] and Freitag et al. [2004].

[10] These publications presented the results of firn cores from single sites. In this study we extend the work by Gerland et al. [1999] and Freitag et al. [2004] with 14 more firn cores from Greenland and Antarctica, covering a broad range of local climate conditions. High-resolution density measurements are obtained with the gamma-attenuation method. We shortly discuss the possible impact of microstructure and impurities on the density and densification. At this point we cannot prove the role of microstructure (on a grain scale) in this study since no microstructure data are available with this resolution. However, the available data allow a profound examination of macrostructural properties of the firn and the densification. Our high-resolution density measurements reveal the following results:

[11] 1. Mean density profiles obtained from high-resolution measurements do only partly display a transition in densification rate at 550,730 and $820-840 \mathrm{~kg} / \mathrm{m}^{3}$.

[12] 2. All firn cores presented here show a second maximum of density variability, as first reported by Gerland et al. [1999]. Accordingly an effect of changes in local climate or weather, as suggested by Li and Zwally [2002], can be excluded. The minimum in variability is reached at mean densities around $600-650 \mathrm{~kg} / \mathrm{m}^{3}$, while the mean density and amplitude of the second maximum in variability varies from site to site.

[13] 3. A more efficient compaction of initially less dense layers leading to a crossover, as suggested by Gerland et al. [1999] and Freitag et al. [2004], can explain the observed density variability and the switch in correlation of density to ECM and brightness. This process of differential compaction also means that the initially dense layers from the surface exhibit lower densities at the firn-ice transition. The highdensity layers which create a sealing effect at the firn-ice transition might originate as low-density layers at the surface. 
Table 1. The 16 Firn Core Sites With Position, Mean Annual Temperature, and Accumulation Rate

\begin{tabular}{|c|c|c|c|c|c|c|c|c|}
\hline Campaign/Region $^{\mathrm{a}}$ & Name & Latitude (deg) & $\begin{array}{l}\text { Longitude } \\
\text { (deg) }\end{array}$ & $\begin{array}{l}\text { Height Above } \\
\text { Sea Level } \\
\text { (m) }\end{array}$ & $\begin{array}{l}\text { Mean Annual } \\
\text { Temperature } \\
(\text { deg C) }\end{array}$ & $\begin{array}{c}\text { Accumulation } \\
\text { Rate }^{\mathrm{b}} \\
\text { (m w.e.) }\end{array}$ & $\begin{array}{c}\text { Years } \\
\text { of Drilling }\end{array}$ & Reference $^{\mathrm{c}}$ \\
\hline \multicolumn{9}{|c|}{ Greenland } \\
\hline NGT & B16 & 75.9402 & -37.6299 & 3040 & -27 & 0.142 & 1993-1995 & 1,2 \\
\hline NGT & B17 & 75.2504 & -37.6248 & 2820 & & & 1993-1995 & 1,2 \\
\hline NGT & B18 & 76.6170 & -36.4033 & 2508 & -30 & 0.104 & 1993-1995 & 1,2 \\
\hline NGT & B21 & 80.000 & -41.1374 & 2185 & -30 & 0.108 & 1993-1995 & 1,2 \\
\hline NGT & B26 & 77.2533 & -49.2167 & 2598 & -30.6 & 0.18 & 1993-1995 & 1,3 \\
\hline NGT & B29 & 76.0039 & -43.4920 & 2874 & -31.6 & 0.153 & 1993-1995 & 1,2 \\
\hline \multicolumn{9}{|c|}{ Antarctica } \\
\hline Berkner Island & B25 & -79.6142 & -45.7243 & 886 & -27 & 0.14 & 1995 & 4 \\
\hline DML & B31 & -75.5815 & -3.4303 & 2669 & -42 & 0.063 & 1997 & 5,6 \\
\hline DML & B32 & -75.0023 & 0.0070 & 2882 & -42 & 0.061 & 1997 & 5,6 \\
\hline DML & B33 & -75.1670 & 6.4985 & 3160 & & 0.044 & 1998 & 5,6 \\
\hline DML & B36/37 & -75.0025 & 0.0684 & 2891 & -44.6 & 0.067 & $2005 / 2006$ & 7 \\
\hline Pre-IPICS & B38 & -71.1621 & -6.6989 & 690 & -18.1 & 1.25 & $2006 / 2007$ & 8 \\
\hline Pre-IPICS & B39 & -71.4083 & -9.9167 & 654 & -17.9 & 0.77 & $2006 / 2007$ & 8 \\
\hline Pre-IPICS & DML95 & -71.5680 & -6.6670 & 540 & -19.2 & 0.55 & $2006 / 2007$ & 8 \\
\hline Pre-IPICS & DML97 & -72.0640 & -9.5583 & 760 & -20.4 & 0.49 & $2006 / 2007$ & 8 \\
\hline Dome C & EDC2 & -75.1000 & 123.35000 & 3233 & -53 & 0.025 & 1999 & 9 \\
\hline
\end{tabular}

${ }^{a}$ NGT, North Greenland traverse; DML, Dronning Maud Land.

${ }^{\mathrm{b}}$ Measured in meters water equivalent depth ( $\mathrm{m}$ w.e.).

${ }^{c}$ Numbers correspond to the following references: (1) Schwager [2000], (2) Wilhelms [1996, 2000], (3) Freitag et al. [2004], (4) Gerland et al. [1999], (5) Sommer et al. [2000], (6) Oerter et al. [2000], (7) EPICA Community Members [2006], (8) J. Schwander and H. Oerter (personal communication), and (9) EPICA Community Members [2004].

[14] 4. The variability at the firn-ice transition increases with increasing mean annual temperature and accumulation rate, whereas the variability at the surface decreases. Lowaccumulation sites also show relatively high near-surface density variability. This observation gives reason to question a direct link between the degree of surface layering and the extent of a nondiffusive zone.

\section{Methods}

\subsection{Material and Instrument}

[15] The high-resolution density profiles of 16 different sites from Greenland and Antarctica are investigated. The firn cores were drilled and measured in a time interval over almost 20 years. The firn cores are from areas which cover a broad range in mean annual surface temperature, accumulation rate and elevation and origin from Greenland and Antarctic Plateau regions but also from Antarctic coastal regions. For further details see Tables 1 and 2.

[16] The density was measured using a nondestructive logging system including a Löffel densimeter [Wilhelms, 1996]. The measured intensity $I$ of the attenuated gamma ray beam through the ice core is converted into a density signal. Using Beer's law, the intensity of the beam in air $I_{0}$, the mass absorption coefficient $\mu_{i c e}=0.085645 \mathrm{~m}^{2} \mathrm{~kg}^{-1} \pm 0.1 \%$

Table 2. Measurement Setups and Data Processing Parameters for the 16 Firn Cores $^{\mathrm{a}}$

\begin{tabular}{|c|c|c|c|c|c|c|}
\hline Campaign/Region & Name & $\begin{array}{c}\text { Year of } \\
\text { Measurement }\end{array}$ & $\begin{array}{c}\text { Activity Source, } \\
1990(\mathrm{GBq})\end{array}$ & $\begin{array}{l}\text { Sampling } \\
\text { Rate (mm) }\end{array}$ & $\begin{array}{c}\text { Point Distance } \\
\text { (mm w.e.) }\end{array}$ & $\begin{array}{c}\text { Averaging } \\
\text { Window Points }\end{array}$ \\
\hline \multicolumn{7}{|c|}{ Greenland } \\
\hline NGT & B16 & $1995 / 1996$ & 25.96 & 3 & 3 & 5 \\
\hline NGT & B17 & $1995 / 1996$ & 111 & 1 & 0.9 & 16 \\
\hline NGT & B18 & $1995 / 1996$ & 111 & 3 & 3 & 5 \\
\hline NGT & B21 & $1995 / 1996$ & 111 & 3 & 3 & 5 \\
\hline NGT & B26 & $1995 / 1996$ & 25.96 & 1 & 0.9 & 16 \\
\hline NGT & B29 & 1995/1996 & 25.96 & 1 & 0.9 & 16 \\
\hline \multicolumn{7}{|c|}{ Antarctica } \\
\hline Berkner Island & B 25 & 1995 & 25.96 & 3 & 3 & 5 \\
\hline DML & B31 & $1997 / 1998$ & 25.96 & 5 & 4.4 & 3 \\
\hline DML & B32 & $1997 / 1998$ & 25.96 & 5 & 4.4 & 3 \\
\hline DML & B33 & 1998 & 25.96 & 5 & 4.4 & 3 \\
\hline DML & B36/37 & $2007 / 2006$ & 111 & 1 & 0.9 & 11 \\
\hline Pre-IPICS & B38 & 2007 & 111 & 1 & 0.9 & 16 \\
\hline Pre-IPICS & B39 & 2007 & 111 & 1 & 0.9 & 16 \\
\hline Pre-IPICS & DML95 & 2007 & 111 & 1 & 0.9 & 16 \\
\hline Pre-IPICS & DML97 & 2007 & 111 & 1 & 0.9 & 16 \\
\hline Dome C & EDC2 & 2008 & 111 & 1 & 0.9 & 11 \\
\hline
\end{tabular}

${ }^{\mathrm{a}}$ More details are given by Wilhelms [1996, 2000]. 

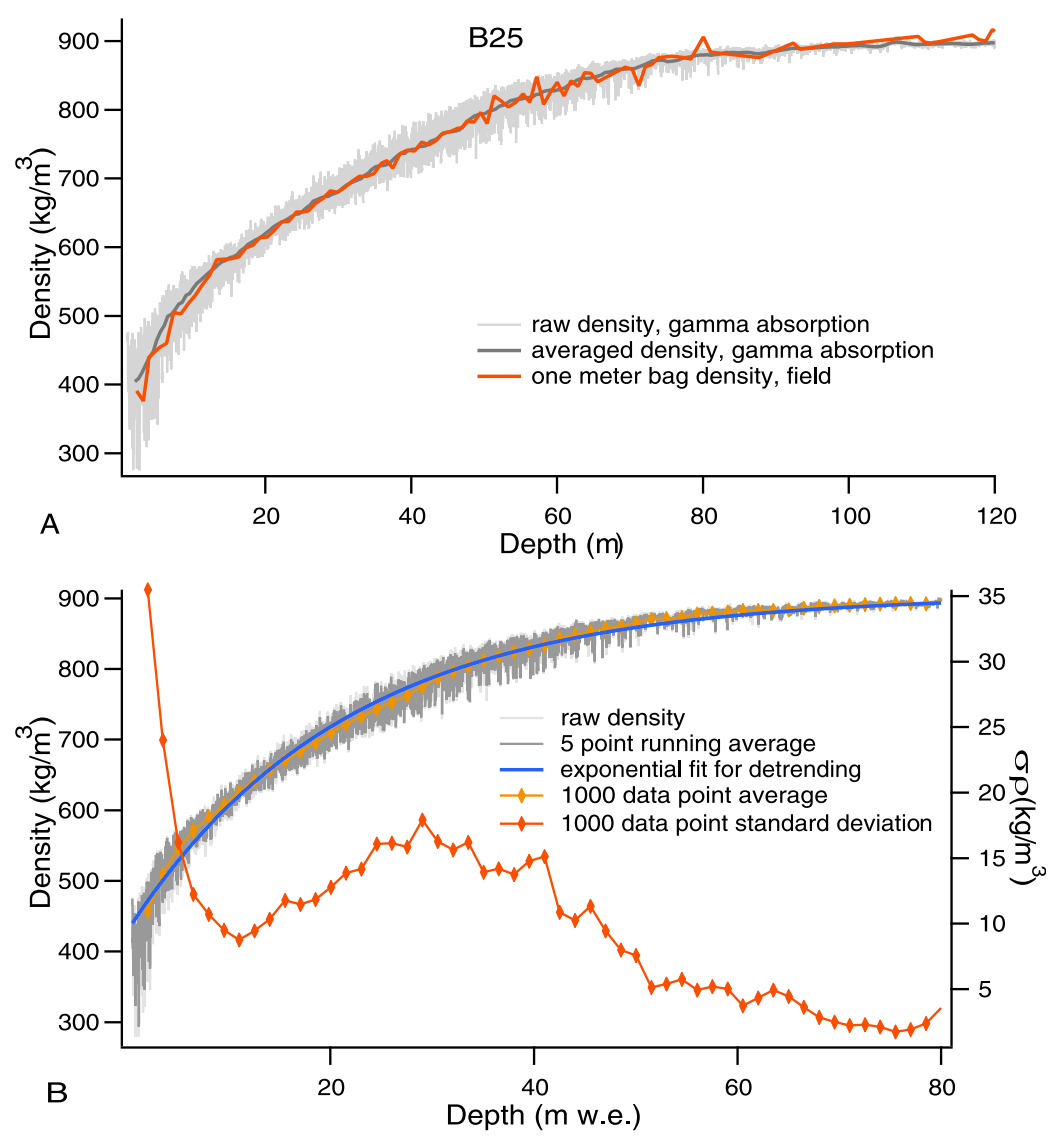

Figure 1. (a) The measured high-resolution (light grey line) density raw data with depth together with the $1 \mathrm{~m}$ average (running mean) from high-resolution density measurements (dark grey line) and the $1 \mathrm{~m}$ bag values measured in the field (red line) for comparison. (b) The high-resolution density raw data with depth in meter water equivalent after resampling to equidistant points (light grey line), together with the smoothed data after applying a running mean average window of size as denoted in Table 2 (dark grey line). The exponential fit for detrending is displayed (blue line) as well as the mean values of a sliding window of 1000 data points (yellow), corresponding to the standard deviation of the sliding window of 1000 data points after detrending (red).

[Wilhelms, 1996, 2000] and the diameter $d$ of the ice core, the density $\rho$ can be calculated by:

$$
\rho=\frac{-1}{d \cdot \mu} \cdot \ln \left(\frac{I}{I_{0}}\right)
$$

Details and background of the method are given by Wilhelms [1996, 2000]. Gerland et al. [1999] and Freitag et al. [2004] discussed density data obtained by this method and compared it to density profiles obtained with computer tomography [Freitag et al., 2004]. Usually two $1 \mathrm{~m}$ long core pieces are put in a cradle for a measurement run. The diameter is measured every $10 \mathrm{~cm}$ manually with a calliper and then interpolated over the length of the core piece. Scratches from core catchers and breaks are documented. All measurements were conducted between temperatures of $-10^{\circ} \mathrm{C}$ and $-35^{\circ} \mathrm{C}$ either in the cold laboratory of the Alfred Wegener Institute (AWI), Bremerhaven, Germany or in the field, using a comparable measurement set up.

\subsection{Data Processing}

[17] After the measured diameter is interpolated and used to calculate the density according to equation (1), the raw data are corrected for core breaks and scratches, by manually removing single outliers and linearly interpolating over the resulting data gaps. Two different processing strategies are used. First, the density versus depth profile is investigated and average values are compared to field data and to the HerronLangway model [Herron and Langway, 1980]. The measured raw high-resolution density is shown in Figure 1a (light grey). A running mean using a sliding window of $1 \mathrm{~m}$ length is calculated (Figure 1a, dark grey line). Comparison with field data of $1 \mathrm{~m}$ long ice core sections yields good agreement (Figure 1a, red line). The mean density determined from high-resolution measurements, noted as mean density in sections 3.1 and 4.1, is compared to density values calculated from the Herron-Langway model.

[18] Secondly, the density profile is converted to water equivalent depth (m w.e.). Again average values are calculated as well as a standard deviation as a measure of density variability. The conversion leads to unequal distances between data points (i.e., low-density snow at the surface corresponds to smaller increments in $\mathrm{m}$ w.e. depth than high-density firn at greater depths). Therefore each density profile is resampled to equidistant points as noted in Table 2 (point 
distance), depending on the sampling rate of the measurements (Figure 1b, light grey line).

[19] The conversion from actual depth to water equivalent depth enables a comparison of the layers from the nearsurface area with layers from greater depths, since the effect of the thinning of layers due to compaction is taken into account. Furthermore the water equivalent depth scale provides a measure of the overburden pressure and enables a comparison of the cores at similar overburden pressures. In order to remove fluctuations or noise on smaller length scales than the layering, the data are smoothed using a moving average window (Figure 1b, dark grey line covering the raw data; window size in Table 2 ). To study the density variability the data are detrended, using an exponential fit (Figure 1b, blue line):

$$
\rho=y_{0}+A_{1} \cdot \exp \left(-\tau_{1} z\right)+A_{2} \cdot \exp \left(-\tau_{2} z\right) .
$$

After detrending, the standard deviation $\sigma_{\rho}$, with a sliding window of size $N=1000$ and a step size of 500 data points (Figure 1b, red line) is

$$
\sigma_{\rho}=\sqrt{\frac{\sum_{i}^{N}\left(\rho_{i}-\bar{\rho}\right)^{2}}{N}},
$$

where $\rho_{i}$ is the density at point $i$ and $\bar{\rho}$ the mean density of window $N$. In order to compare the different cores and their standard deviation we have several possibilities to define $N$ : we either calculate the standard deviation over a fixed water equivalent depth interval or over a fixed time interval. The former results in the comparison of different time intervals, the latter in the comparison of different depth intervals. We calculated the standard deviation by taking a fixed number of data points $(N=1000)$, over which the standard deviation is calculated. For a sufficiently large $N$, the calculated standard deviation is independent of the window size.

[20] For the same window size, a mean density of the depth-density profile in water equivalent depth is calculated (Figure 1b, yellow line). This value is the mean density at a certain depth (m w.e.) corresponding to the standard deviation at this depth (m w.e.). We refer to this value as mean density of the density-depth profile in water equivalent depths in sections 3.2, 4.2, 4.3 and 4.4.

[21] Martinerie et al. [1992] introduced an empirical linear relationship of measured air volume in ice cores to annual mean surface temperature and the critical density $\rho_{\text {crit }}$ at which the air isolation occurs. We use this relation to calculate the mean close-off density $\rho_{\text {crit }}$ at our firn sites:

$$
\rho_{\text {crit }}=\left(\frac{1}{\rho_{\text {ice }}}+7.6 \times 10^{-4} \times T-0.057\right)^{-1},
$$

with $\rho_{\text {ice }}=917 \mathrm{~kg} / \mathrm{m}^{3}$ the density of pure ice and $T$ the annual mean surface temperature in Kelvin. Knowing the close-off density, the measured variability $\sigma_{\rho}$ at that density is then determined from the measurements.

[22] To test the assumption of a relationship between the layering at the surface and the extent of the nondiffusive zone, we compare the density variability at the surface with the density variability at the firn-ice transition. The latter is defined by the mean density obtained from equation (4) and the related standard deviation. To determine surface variability we first define intervals for which the standard deviation is calculated. We chose to show more than one interval to illustrate the extremely different accumulation rates at the sites. Therefore from each site, $1 \mathrm{~m}$ depth intervals starting from the surface to $6 \mathrm{~m}$ depth are converted to water equivalent depth and the standard deviation is calculated following equation (3). This time, $N$ is the number of points within each of the $1 \mathrm{~m}$ long intervals.

[23] To estimate the relative error of the density measurements, the errors in each term of equation (1) have to be considered. The relative error in density has been estimated as $4.24 \%$ at the top $2 \mathrm{~m}$ and $1.47 \%$ at $100 \mathrm{~m}$ depth for the cores B16,B18, B31, B32, B33 [Wilhelms, 2000]. The resulting absolute errors are $10-15 \mathrm{~kg} / \mathrm{m}^{3}$ in the upper meters and $8-12 \mathrm{~kg} / \mathrm{m}^{3}$ in greater depths. For cores B17, B19 and B21, B38, B39, DML95, DML97, B36/B37 and EDC2 the relative error is reduced to $1.65 \%$ in the upper $2 \mathrm{~m}$, decreasing to $0.66 \%$ at $100 \mathrm{~m}$ depth [Wilhelms, 1996, 2000]. The error reduces because of the use of either a stronger gamma ray source or a higher-resolution measurement [Wilhelms, 1996, 2000]. This leads to absolute values around $5-6 \mathrm{~kg} / \mathrm{m}^{3}$ for all depths. The standard deviation is calculated over 1000 data points and thus averages over the random error associated with each single measurement point. We therefore assume that the standard deviation obtained by the processing described above gives a good measure of the variability in density due to the different strata in the firn. The standard deviation as a term of density variability has been used by Gerland et al. [1999], Freitag et al. [2004] and Fujita et al. [2009]. For more detailed discussion of error estimation of the gamma attenuation method see [Wilhelms, 1996, 2000] and [Breton et al., 2009].

\section{Results}

\subsection{Mean Density}

[24] The mean density profiles obtained from highresolution data are shown and discussed with respect to changes in densification rate at different critical densities and with respect to predicted profiles using the HerronLangway model.

[25] First, the measured high-resolution density profiles of the B25 core [Gerland et al., 1999] and the B26 core [Freitag et al., 2004] are displayed, together with the $1 \mathrm{~m}$ averages (Figure 2). The previously published data were included in this study to show that applying the above described procedures yields similar results as shown in earlier publications. All mean density profiles are shown and the commonly assumed mean critical densities, at which a change in densificationrate is expected, are indicated with dashed lines (Figure 3). For some sites the Herron-Langway model was used to predict density and the results are compared to the mean density profiles obtained from high-resolution density measurements (Figure 4).

[26] Assuming a change in densification rate at the critical densities of 550,730 or $820-840 \mathrm{~kg} / \mathrm{m}^{3}$, the slope of the density-depth profiles should show a distinct change at these densities. This is expressed in the Herron-Langway model, where the density increases with different rates as a function of depth below and above a density of $550 \mathrm{~kg} / \mathrm{m}^{3}$ [Herron and Langway, 1980]. Hence, even though we do 

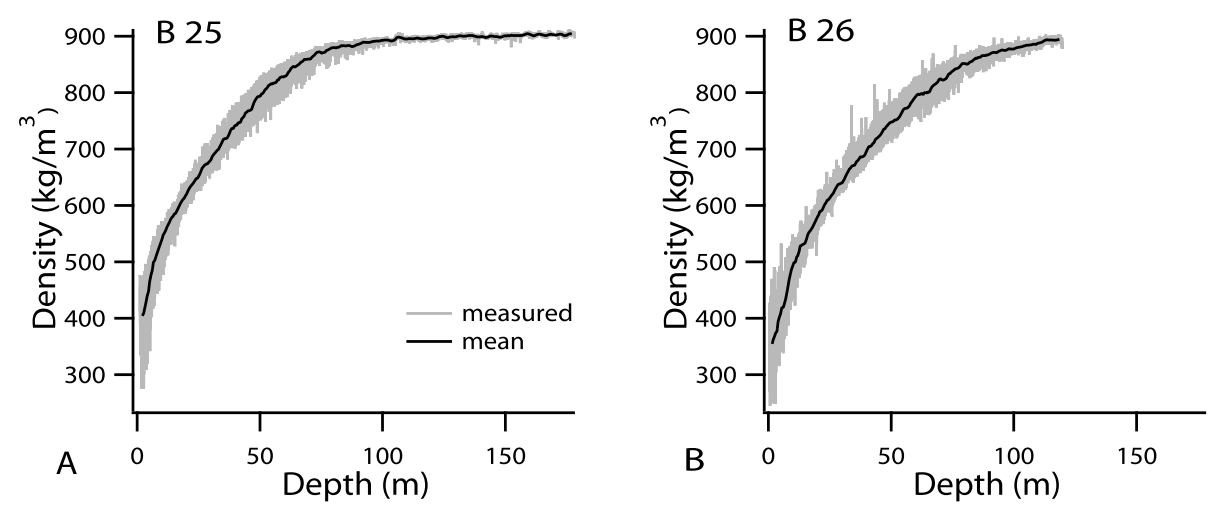

Figure 2. High-resolution density profiles (grey line) of B25 [after Gerland et al., 1999] and B26 [after Freitag et al., 2004], together with the $1 \mathrm{~m}$ average (black line). The large variability in the density becomes visible, even at greater depths.

not consider the increase in density as a function of time, we can study the density-depth profiles in terms of an abrupt change in the slope, when a critical density is reached (Figures 3 and 4). We observe a weak transition in the slope of the density-depth profiles at densities between 550 and $580 \mathrm{~kg} / \mathrm{m}^{3}$ for high-accumulation sites such as DML95 (Figure 3), whereas the cores B26 and B29 show this transition at much lower densities below $500 \mathrm{~kg} / \mathrm{m}^{3}$; the same holds for B36/B37 (Figure 4). The B25 core shows a distinct change in the slope at approximately $550 \mathrm{~kg} / \mathrm{m}^{3}$ but the EDC2 core shows no abrupt change at all (Figure 4). A change of densification rate at $730 \mathrm{~kg} / \mathrm{m}^{3}$ is not observed in any of our density-depth profiles. Also a distinct change at 820 $840 \mathrm{~kg} / \mathrm{m}^{3}$ is not apparent, however a slow-down in density increase is present for densities higher than $840 \mathrm{~kg} / \mathrm{m}^{3}$.

[27] Some examples of the mean density profile and the predicted profiles using the Herron-Langway model are plotted in Figure 4. The profiles of B25, B29 and B26 with moderate temperatures of $-27^{\circ} \mathrm{C}$ and approximately $-30^{\circ} \mathrm{C}$ and accumulation rates of $0.14-0.18 \mathrm{~m}$ w.e. per year are

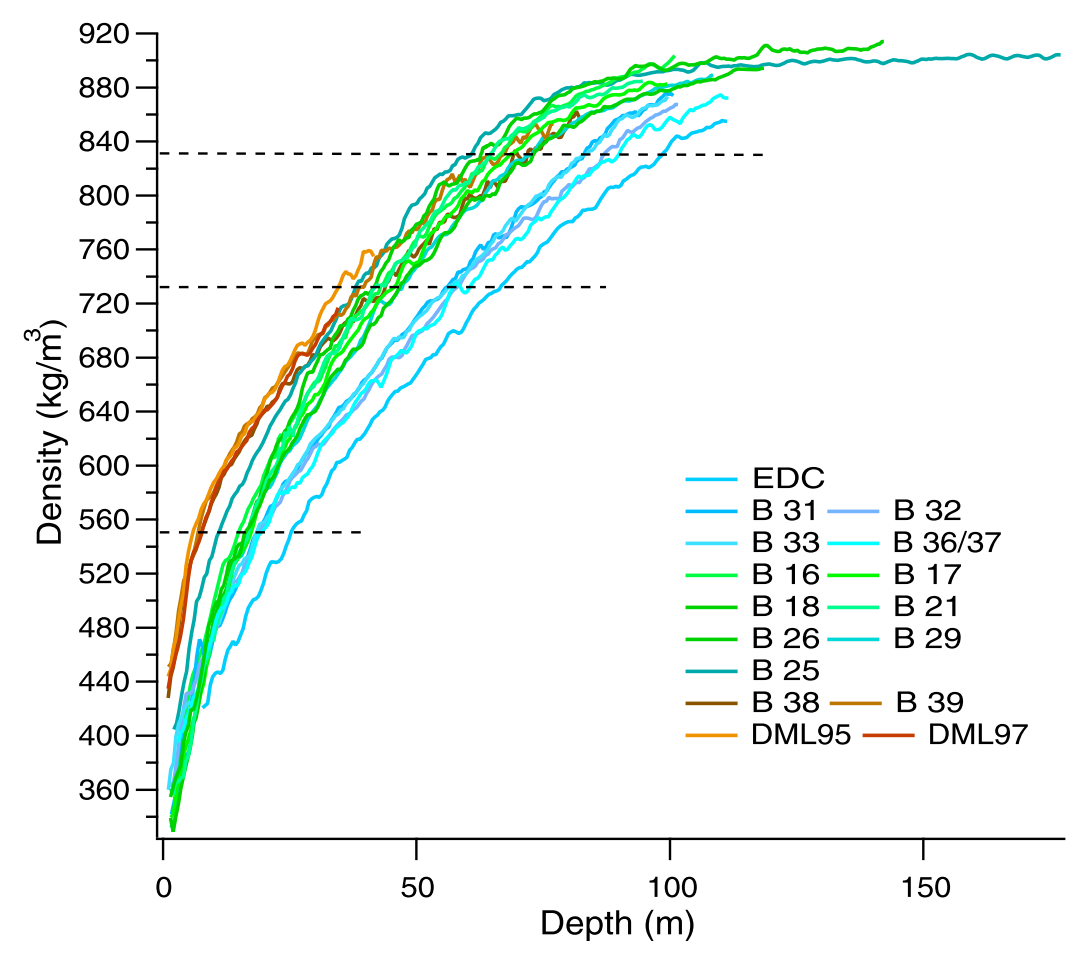

Figure 3. Mean density profiles (1 m running mean average). Low-accumulation sites are plotted in blue, medium accumulation sites in green, and high-accumulation sites in brown. Commonly considered "critical density" values of 550,730 , and $820-840 \mathrm{~kg} / \mathrm{m}^{3}$ are indicated by dashed lines. For most of the cores a transition at $550 \mathrm{~kg} / \mathrm{m}^{3}$ is not obviously detectable. A transition at density around $730 \mathrm{~kg} / \mathrm{m}^{3}$ is not visible in any profile. For most of the cores a change in densification rate occurs at densities above $840 \mathrm{~kg} / \mathrm{m}^{3}$, but a distinct transition is not apparent. 

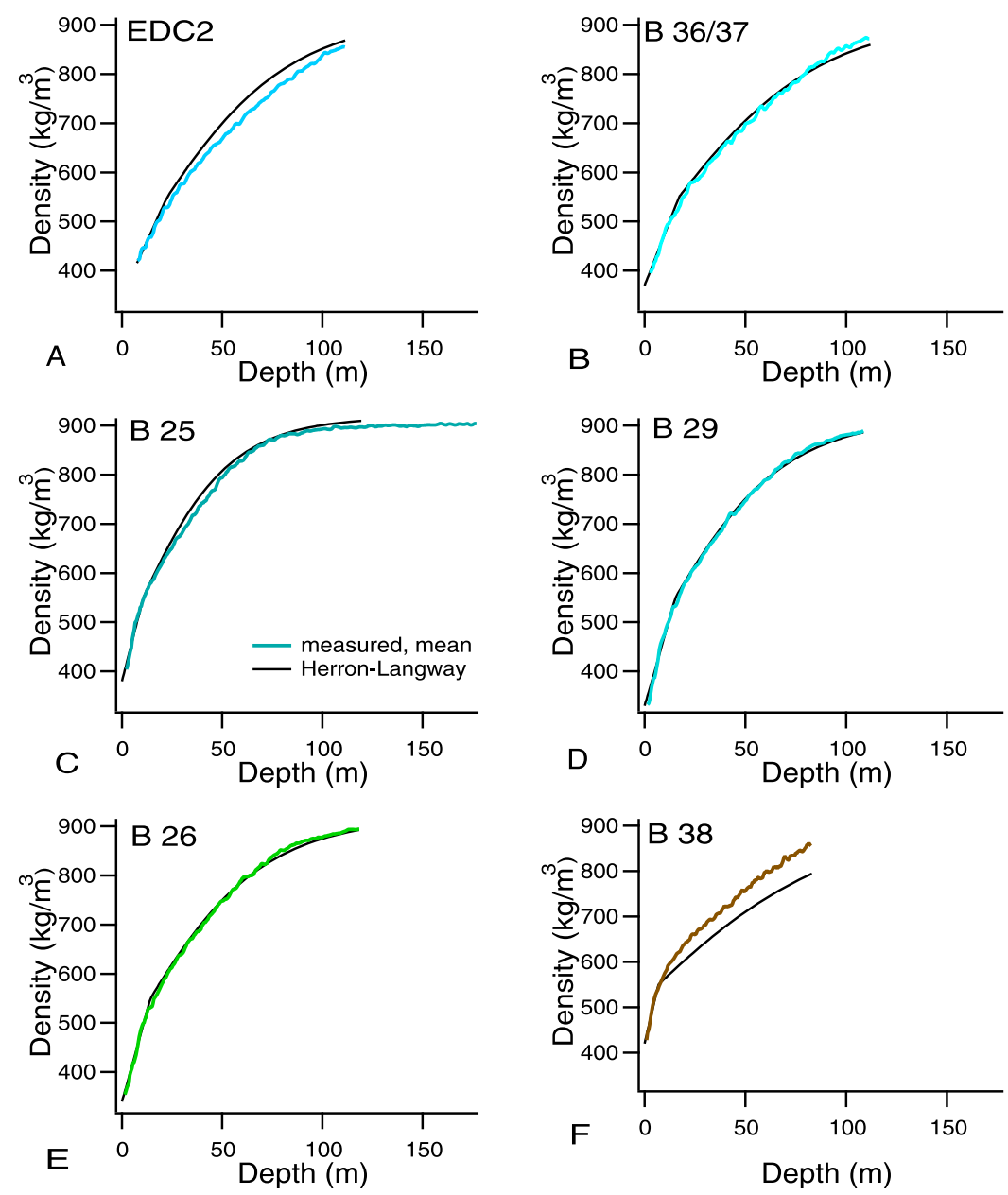

Figure 4. (a-f) Selected mean density profiles in comparison to modeled density profiles using the Herron-Langway model (black line). The Herron-Langway model reproduces the profiles of the B25, B26, and B29 cores with moderate mean annual temperatures and accumulation rates (Figures 4c-4e) well. But the model fails for the EDC2 core with low accumulation rate and temperature and the B38 core with high accumulation rate and temperature (Figures $4 \mathrm{a}$ and $4 \mathrm{f}$ ).

predicted fairly well (B25, B26, and B29), but for the EDC2 site, the Herron-Langway model overestimates the measured density. This leads to a 5-6 $\mathrm{m}$ offset in the depth at which the density of $840 \mathrm{~kg} / \mathrm{m}^{3}$ is reached. The firn is older when reaching this density than the model predicts. On the other hand, the Herron-Langway model underestimates the densification at B38. The model run ends at a mean density of approximately $794 \mathrm{~kg} / \mathrm{m}^{3}$ at $83 \mathrm{~m}$ depth. This density is obtained in the mean measured profile at a depth of approximately $59 \mathrm{~m}$. The firn approaching a certain density is much younger than predicted by the model (Figure 4).

\subsection{Density Variability}

[28] The layering of polar firn induces a variability observed in high-resolution density profiles. The variability changes with increasing depth and mean density (Figure 5). The standard deviation, $\sigma_{\rho}$, as a measure of this layering is shown with water equivalent depth (Figure 6a) and with mean density of the density-depth profile in meters w.e. (Figure 6b). The behavior of $\sigma_{\rho}$ at different local climate conditions is displayed in Figure 7.
[29] The evolution of a typical high-resolution density profile, here B26, is shown in detail (Figure 5). B26 represents a typical firn-core site from the Greenland plateau, with a moderate mean annual temperature of $-30.6^{\circ} \mathrm{C}$ and accumulation rate of $0.18 \mathrm{~m}$ w.e. per year. Visually, the density variability changes its shape, amplitude and frequency with increasing density and depth. Large fluctuations are observed at lower mean densities (Figure 5, 5 and $8 \mathrm{~m}$ depth interval). At higher mean densities around $600 \mathrm{~kg} / \mathrm{m}^{3}(20 \mathrm{~m})$ the amplitude decreases, but for even higher densities around $700 \mathrm{~kg} / \mathrm{m}^{3}$ the amplitudes increase again (25 and $40 \mathrm{~m}$ depth). The variability vanishes at densities above $800 \mathrm{~kg} / \mathrm{m}^{3}$ (Figure 5, $75 \mathrm{~m}$ depth).

[30] The variability, $\sigma_{\rho}$, with depth and increasing mean density (of the density-depth profile in water equivalent depth) is displayed for all firn cores (Figure 6). The amplitude reaches a minimum at a depth of approximately $10 \mathrm{~m}$ w.e. and then increases again. This yields a second relative maximum before it finally falls toward zero (Figure 6a). The minimum in density variability occurs at mean densities between 600 $650 \mathrm{~kg} / \mathrm{m}^{3}$ (Figure $6 \mathrm{~b}$ ), whereas the mean density of the 


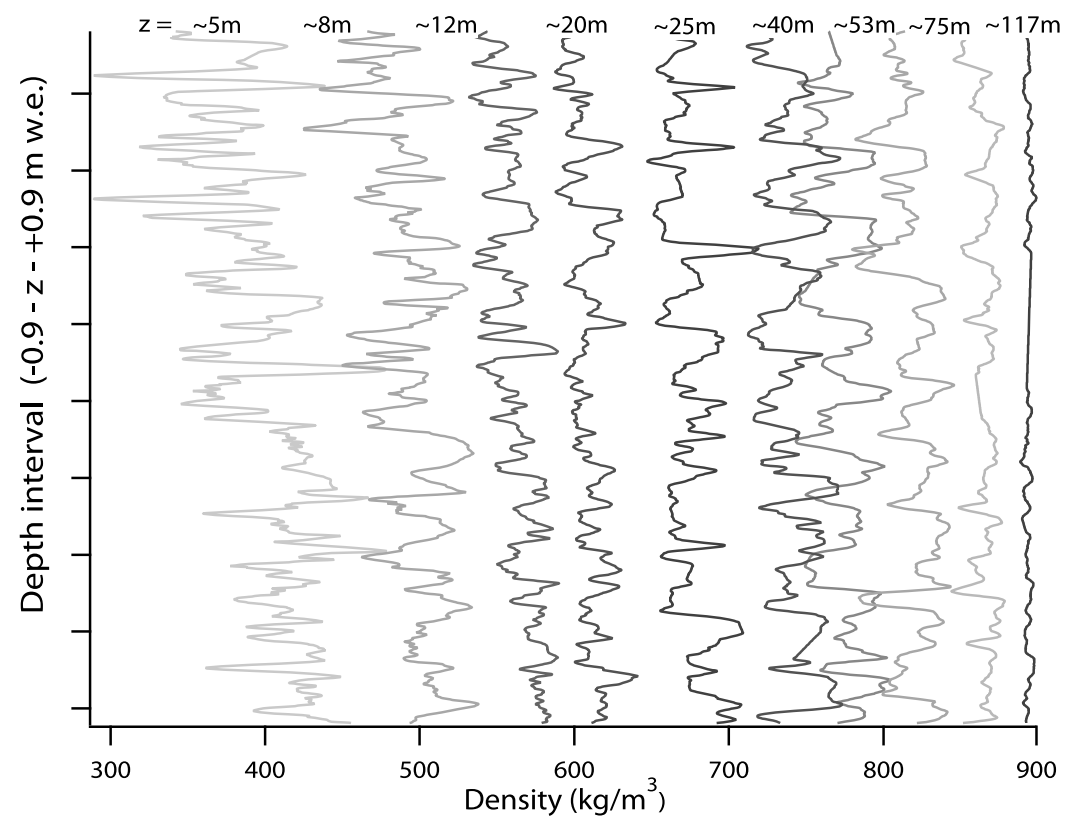

Figure 5. Details of the high-resolution density of B26 core. This core represents a typical firn core from the Greenland plateau, with moderate mean annual temperature and accumulation rate. From left to right the mean density and depth increase. Each profile covers $1.8 \mathrm{~m}$ depth w.e., which equals approximately 10 years at this site. In the upper part ( 5 and $8 \mathrm{~m}$ depth) the density variations are characterized by large amplitudes and random frequencies. Toward greater depths $(20 \mathrm{~m}$ depth) the amplitudes decrease. Below, the amplitudes increase again and more regular frequencies seem to appear (25-53 m depth). Below $53 \mathrm{~m}$ depth the variability decreases until it vanishes at depths of $75 \mathrm{~m}$.

following second maximum in variability seems to vary slightly. At mean densities of the firn-ice transition some cores show high amplitudes in $\sigma_{\rho}$ (B38 and B39, for example) while for other cores the amplitude is decreasing (EDC2 and $\mathrm{B} 36 / \mathrm{B} 37)$.

[31] In order to get a better overview of the influence of local climate conditions, the profiles have been sorted into five groups, Figures $7 \mathrm{a}-7 \mathrm{e}$, of similar annual mean temperature and accumulation rate. In all five groups the structure of rapid decrease of $\sigma_{\rho}$ to a minimum at $600-650 \mathrm{~kg} / \mathrm{m}^{3}$ and a second maximum below is found. B25 is plotted in two groups. The density variability decrease of B25 in the upper core is similar to the Antarctic cores, while the second maximum is more consistent with the Greenland cores, as are the climate conditions. Finally, we calculated the average for each group to determine typical behavior (Figure 7f). For comparison the averages of Figures $7 \mathrm{a}-7 \mathrm{e}$ can be seen in Figure 7f. Except for Figure 7c, the drop to the minimum is similar, but the patterns clearly diverge in extent and amplitude of the second maximum. Whereas Figures $7 \mathrm{a}, 7 \mathrm{~b}, 7 \mathrm{c}$, and $7 \mathrm{~d}$ differ in amplitude of the second maxima, but not that much in position, Figure 7e shows the second maximum at distinctively larger mean densities.

[32] In summary, all firn cores, covering a broad range of climate conditions, show a similar rapid decrease followed by a second maximum of density variability. The cores show a similar structure of $\sigma_{\rho}$ above the minimum. The mean density of the minimum variability seems to be always at approximately $600-650 \mathrm{~kg} / \mathrm{m}^{3}$, whereas the magnitude and the position of the second maximum seem to vary according to the environmental climatic conditions of a site.

\section{Discussion}

\subsection{Mean Density}

[33] According to the literature, depth-density profiles should show changes in the slope at densities of 550,730 and $820-840 \mathrm{~kg} / \mathrm{m}^{3}$. We expected the mean density-depth profiles from high-resolution density measurements to clearly show these transitions. The first transition in densification rate is suggested at a mean density of $550 \mathrm{~kg} / \mathrm{m}^{3}$ [Herron and Langway, 1980] as a result of particle rearrangement gaining maximum packing density [Arnaud et al., 2000]. In our results the density at which this change occurs varies from densities below $500 \mathrm{~kg} / \mathrm{m}^{3}$ at B36/B37 or B29 up to densities close to $600 \mathrm{~kg} / \mathrm{m}^{3}$ at B38 (Figure 4). It seems that the critical density, at which the densification rate changes, varies at the different sites. Different snow and firn types may exhibit a different density at which the compaction mechanism changes. At a single site with strong layering each layer will react differently to the applied load [Freitag et al., 2004; Alley et al., 1982]. Transitions at the other densities of 730 and $820-840 \mathrm{~kg} / \mathrm{m}^{3}$ are not clearly detectable. It is reasonable to assume that different microstructural processes and deformation patterns take place at all depths and the dominance of each of these processes will shift rather smoothly from one to another within the firn column [Kipfstuhl et al., 2009]. Different processes can also occur concurrently [Arnaud et al., 1998; Salamatin et al., 2009] and 

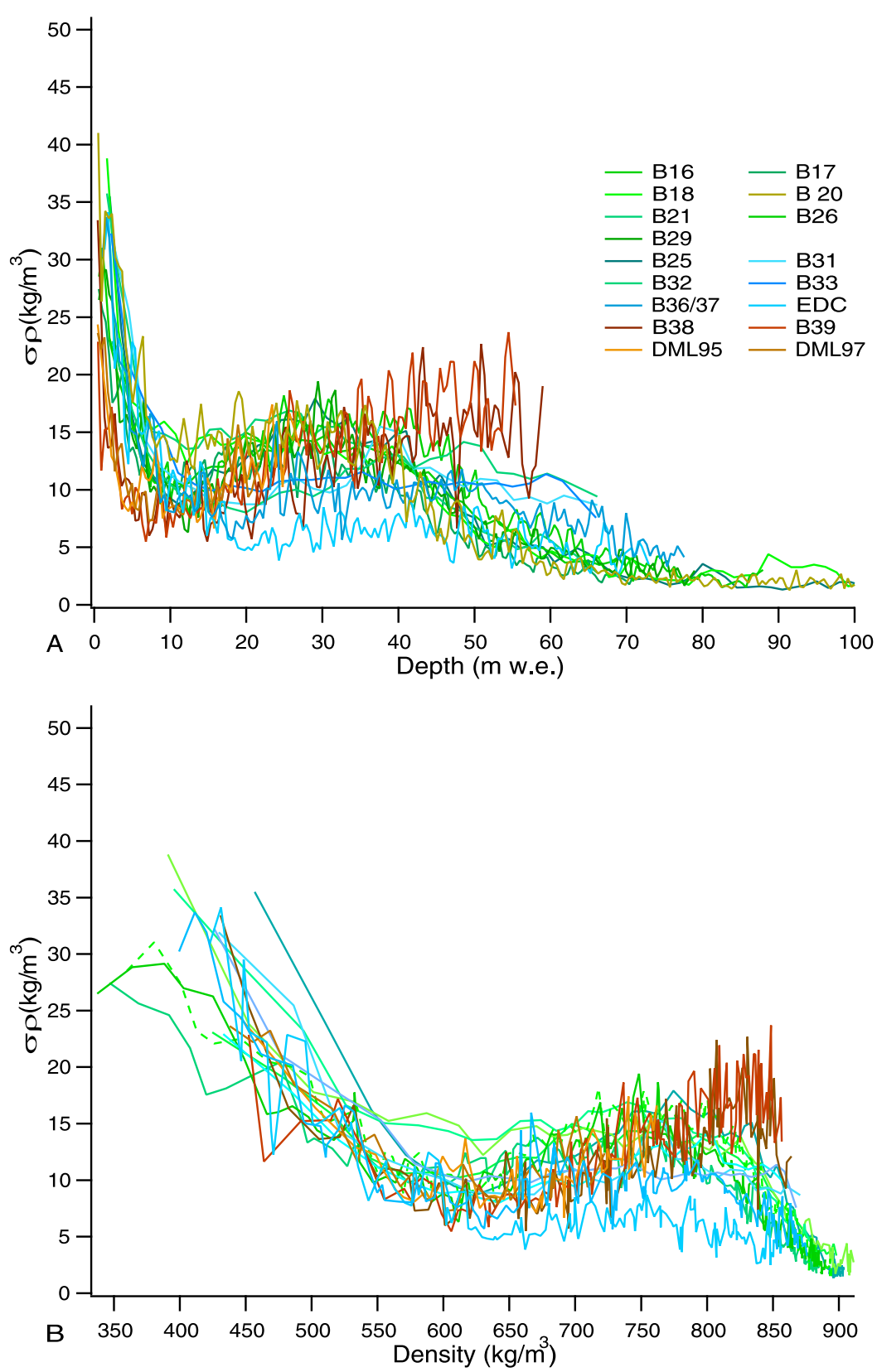

Figure 6. Measured density variability $\sigma_{\rho}$ of all cores as a function of depth in (a) meters w.e. and (b) mean density. All profiles show a rapid drop in $\sigma_{\rho}$ with a minimum at approximately $10 \mathrm{~m}$ w.e. depth (Figure 6a). This minimum occurs at mean densities of $600-650 \mathrm{~kg} / \mathrm{m}^{3}$ (Figure $6 \mathrm{~b}$ ) and is followed by a second maximum in $\sigma_{\rho}$, that varies for the different cores. In order to get a more clear and distinct picture, the profiles are plotted within different temperatures and accumulation rate ranges in Figure 7.

critical densities, marking a transition of the dominance of microstructural processes, can vary over a large density range [Johnson, 1998].

[34] The firn cores representing climate conditions considered in the setup of the Herron-Langway model are very well reproduced by the model (Figure 4). For a density-depth relationship at medium climate conditions this rather simple, phenomenological model is still applicable, even if a sharp transition at a mean density of $550 \mathrm{~kg} / \mathrm{m}^{3}$ is not apparent in most of the profiles presented here. Arnaud et al. [2000] showed that the maximum packing density (theoretically $\left.550 \mathrm{~kg} / \mathrm{m}^{3}\right)$ is temperature-dependent. It decreases with decreasing annual mean temperature of a site. This would explain the range of densities at which a change in the slope in the density-depth profile can be observed in our data. Decreasing or increasing this critical density would probably reveal a better fit of the Herron-Langway model with the EDC2 or B38 firn core data. Salamatin and Lipenkov [2008] and Salamatin et al. [2009] find the critical density at generally higher densities, corresponding to the cessation of particle rearrangement at the closest packing density. They explain the lower critical density of $550 \mathrm{~kg} / \mathrm{m}^{3}$ to be only an 

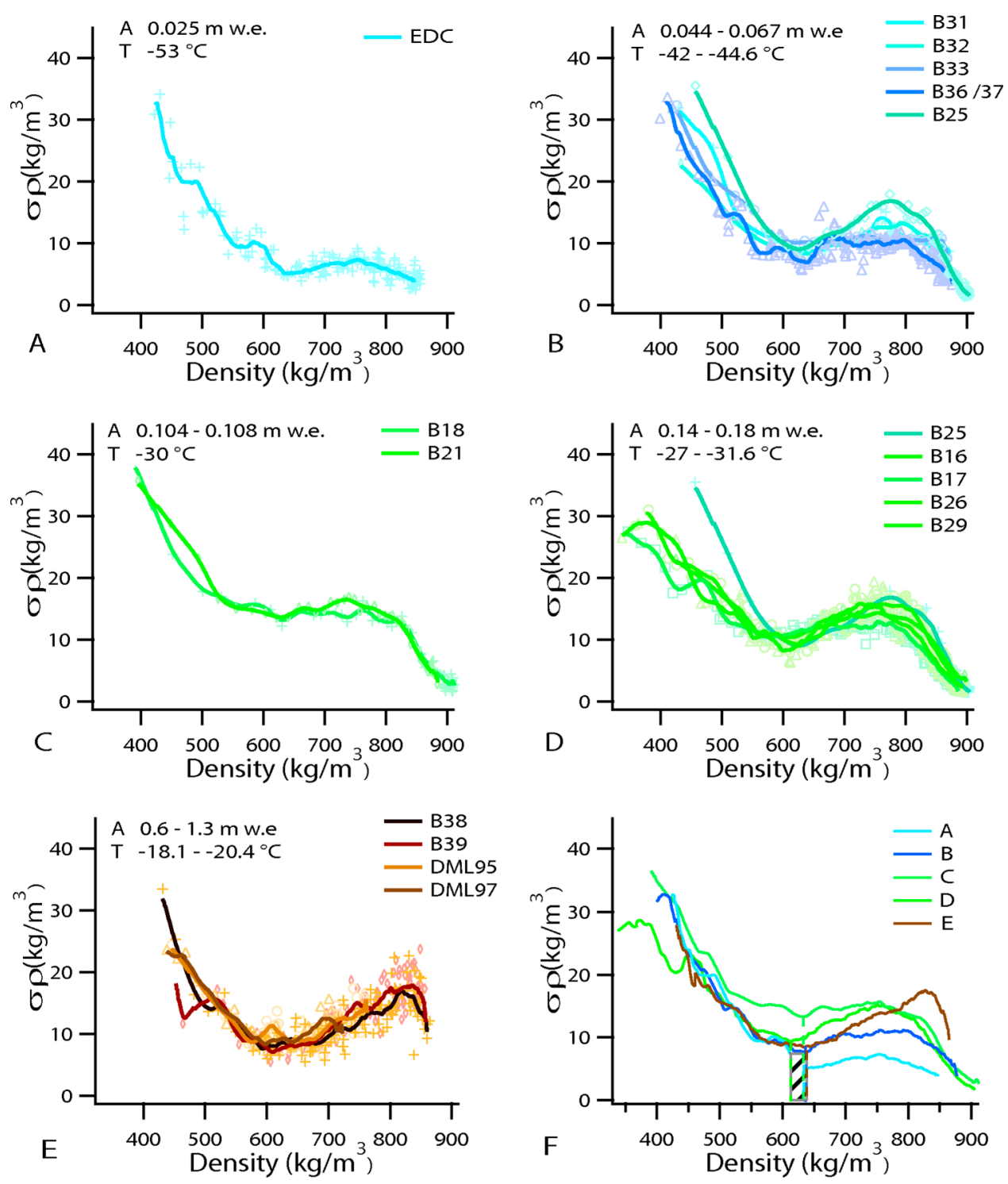

Figure 7. $(\mathrm{a}-\mathrm{f})$ Measured $\sigma_{\rho}$ of the firn cores grouped by temperature and accumulation rate intervals. The lowest temperature and accumulation rate (EDC2) is shown in Figure 7a, and the second lowest DML) is shown in Figure 7b. The low-accumulation sites from Greenland are shown in Figure 7c; note that the minimum is not well developed. The moderate Greenland cores are shown in Figure 7d. The B25 core is plotted in Figures $7 \mathrm{~b}$ and $7 \mathrm{~d}$, since the drop seems to better fit with the DML cores, whereas the second maximum fits fairly well to the Greenland cores. Finally, Figure 7e shows the pre-IPICS cores with highest temperatures and accumulation rates. In Figure $7 \mathrm{f}$ the averaged profiles of each of the groups are plotted. The mean density of the minimum is restricted to $600-650 \mathrm{~kg} / \mathrm{m}^{3}$ (highlighted area).

intermediate stage in which particle rearrangement and plasticity work together, as has been proposed by Ebinuma and Maeno [1987]. No such sharp transitions at densities between 640 and $680 \mathrm{~kg} / \mathrm{m}^{3}$, as were found with the model by Ebinuma and Maeno [1987], are identified in our measured profiles.

[35] The Herron-Langway model included firn cores from a broad range of local climate conditions, including South Pole and Vostok at the lower end of accumulation rate and surface temperature range [Herron and Langway, 1980]. Nevertheless, the model is not applicable to the conditions at Dome $\mathrm{C}$ and to those at the pre-IPICS (International Partnerships in Ice Core Sciences) core sites (i.e., B38). One possible explanation for the distinct deviation of the Dome $\mathrm{C}$ firn core is the different deposition and local climate pattern. So-called diamond dust accomplishes much of the accumulation at Vostok or Dome Fuji, whereas the mass input at Dome $\mathrm{C}$ is dominated by precipitation from synoptic-scale weather systems. The problem of extending empirical models to a broader range of climate conditions has been discussed earlier [Arnaud et al., 2000; Martinerie et al., 1992]. Our data emphasize the need for a physical model [Arnaud et al., 2000; Salamatin and Lipenkov, 2008; Salamatin et al., 2009], but the high-resolution measurements need to be considered in the overall concept of critical densities. 

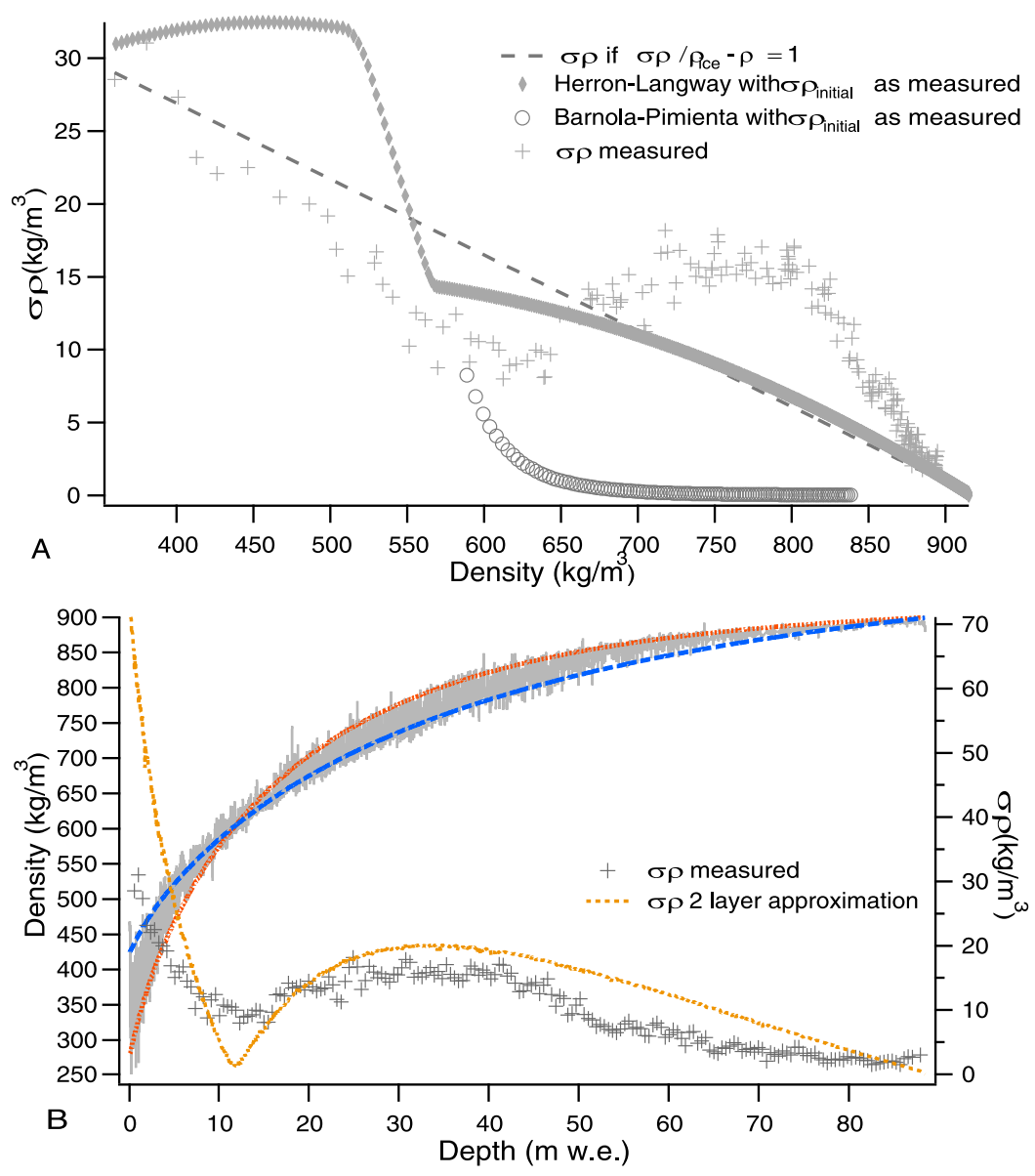

Figure 8. (a) Measured (crosses) and modeled $\sigma_{\rho}$ of B26. We show modeled $\sigma_{\rho}$ when assuming a linear drop of $\sigma_{\rho}$ with increasing $\rho$ (dashed line), modeled $\sigma_{\rho}$ using the Herron-Langway model with two different starting densities (diamonds), and $\sigma_{\rho}$ when applying the Pimienta model, starting at a density of $550 \mathrm{~kg} / \mathrm{m}^{3}$ (circles). Three different stages of the latter occur because of the set up of the Herron-Langway model (see text). (b) The high-resolution density profile of B26 is shown with the resulting $\sigma_{\rho}$ (grey). In addition, two exponential fits are indicated, one starting at lower densities (orange line) and the other starting at higher densities (blue line). Because of different rates in densification, the modeled density profiles cross each other and deviate from each other once more below the crossover depth. Toward the density of ice both fits converge. The resulting $\sigma_{\rho}$ is plotted with brown dots.

\subsection{Density Variability}

[36] Whenever a granular medium compacts, the mean density increases. What happens to the density variability is not known. To our knowledge no work is published that investigates the densification of a granular medium until pore closure. If we assume homogenous compaction with similar densification rates for different layers in a granular stratified medium, we would expect a steady decrease in variability. The densities of low-density and high-density layers originating at the surface increase steadily. Thus, their density values converge with a corresponding reduction in variability and obtain a common value at the density of ice (Figure 8a, dashed line).

[37] We applied two densification models to look at the model behavior in terms of density variability. The HerronLangway model [Herron and Langway, 1980] is parameterized with mean annual temperature and accumulation rate. We can use different surface densities to simulate variability.
By starting with two layers of different density at the surface, we obtain three stages in the evolution of $\sigma_{\rho}$ (Figure 8a, diamonds). In the first stage, the linear increase in density of the two layers is similar, giving no change in $\sigma_{\rho}$, in the second stage, the layer with the initially higher density has already passed the density of $550 \mathrm{~kg} / \mathrm{m}^{3}$ and continues to densify at an exponential rate, while the other layer still experiences linear growth. This leads to a rapid drop in $\sigma_{\rho}$ in the second stage. At the third stage, the second layer has entered the exponential growth regime, and $\sigma_{\rho}$ decreases almost linearly with depth.

[38] The model introduced by Barnola and Pimienta [Barnola et al., 1991] includes an empirical function that considers structural variations during densification [Arnaud et al., 2000]. It starts at a density of $550 \mathrm{~kg} / \mathrm{m}^{3}$. We used measured values for $\sigma_{\rho}$ at mean density of $550 \mathrm{~kg} / \mathrm{m}^{3}$ to start the model. The model produces an exponential drop of $\sigma_{\rho}$ (Figure 8a, circles). Neither of the two employed models can 
reproduce or explain the measured evolution of density variability (Figure 8a, crosses).

[39] The driving force for the densification in the upper part of the firn column is the overburden pressure due to ongoing accumulation of new snow on top of each layer. The overload pressure is determined by the density and thickness of the layers on top. Thus the water equivalent depth gives a measure of the overburden pressure and enables a comparison of the driving force at the different sites. Until the minimum variability at approximately $600-650 \mathrm{~kg} / \mathrm{m}^{3}$ or approximately $10 \mathrm{~m}$ w.e. depth is reached, the variability profiles for all sites are similar (Figure 6a), but below, this depth, density variability diverges.

[40] If we assume that the overburden pressure determines the densification rate down to the variability minimum, the explanation for the observed densification behavior is the manner in which fine and coarse firn structures respond to load [Alley et al., 1982]. Whereas coarse crystals are joined by relatively wide necks to few neighbors, crystals in fine firn tend to be more spherical and are joined by narrow necks to many neighbors. Thus the former structure is far from closest packing and will undergo significant particle rearrangement under an applied load, whereas the latter is more stable [Alley et al., 1982]. Gow [1974] observed firn layers with low density, corresponding to coarse-grained layers, to show less strength to overload pressure than high-density firn, corresponding to fine grains. The surface layers with different densities compact at different rates, the low-density layers faster than the high-density layers, leading to a fast decrease of $\sigma_{\rho}$ until a minimum in density variability is reached. At this minimum in variability the layers have the same density. Continuous densification with different rates leads to equal densities of the layers at a certain depth (crossover), after which the initially low-density layers become denser at a faster rate and exhibit higher densities than the original highdensity layers.

[41] By applying a simple exponential fit to the minimum and maximum densities of the high-resolution profile with a crossover at a mean density of approximately 600 $650 \mathrm{~kg} / \mathrm{m}^{3}$, we can highlight the different compaction rates and the resulting variability (Figure $8 \mathrm{~b}$ ). We do not consider to what extent the low- and high-density layers contribute to the mean density. A better approach could be obtained by using equation (2), where the depth-density relation is represented by two coefficients and amplitudes, which would have the physical meaning of the different densification rates.

[42] Currently, few detailed microstructural data are available. Freitag et al. [2004] showed that the negative grain size-density correlation observed in the near-surface firn switches to a positive correlation below the minimum at the B26 core. Below the crossover, high-density layers contain large grains [Freitag et al., 2004], whereas in the nearsurface layers, low-density layers are usually characterized by large grain sizes. This implies that high-density layers at the firn-ice transition do not necessarily result from highdensity layers at the surface and vice versa. Fujita et al. [2009] also find a switch in density and structural anisotropy obtained from microstructure analysis. The switch in the correlation of density and backscattered light, as observed by Hawley and Morris [2006] at depths of approximately $20 \mathrm{~m}$ could also be explained by such a crossover of coarse-grained and fine-grained firn layers in their densities. Of course firn consists of more than these two example layers and not all will show such a relationship in grain size and density-increase. Nevertheless, it can be hypothesized that the two examples (lowest and highest density) determine the boundary values in which the density variability is created.

[43] Below the minimum, the profiles of $\sigma_{\rho}$ diverge considerably. It is apparent that the overload pressure is no longer the determining factor below this depth. The amplitudes in variability clearly increase again, but not as a function of overload pressure. Other factors, independent from the load, seem to modulate the density variability at this point. The firn cores cover different time intervals, from less than 60 years (B38) to more than 2900 years (EDC2). Accordingly, the behavior of the density variability is not a local climate signal, because we study different time series intervals, but a structural property of layered firn compaction.

[44] A crossover in density of initially coarse-grained, low-density layers and fine-grained, high-density layers, as discussed above, could be one possible explanation. Highresolution grain size data are needed to examine the impact of grain size on the densification of the different layers. Another possibility could be the inclusion of impurities or chemistry into the firn. The interaction of impurities with the firn is rarely investigated. From ice core data the coherence of high dust concentrations with very small grains in the ice matrix is known, which indicates an impact of impurities on physical properties of the ice [Svensson et al., 2005]. Also microstructural parameters apparent in single layers, such as grain shape or textural anisotropy might come to play a role, after a certain density or grain geometry is obtained. Salamatin et al. [2009] showed the importance of grain size and coordination number in the densification process and thus in the determination of the close-off density and depth. Both impurities and microstructure can alter the densification rate of the firn. The analysis of this impact is beyond the scope of this paper, but a topic of future research.

\subsection{Variability at the Firn Ice Transition}

[45] In order to test the assumption of a direct link of surface layering to the variability at the firn-ice transition, related to an extension of a nondiffusive zone [Landais et al., 2006], we compare the density variability at the firnice transition with the density variability at the surface and link it to the mean annual temperature and accumulation rate. We calculate the mean densities for air enclosure, using equation (4) and determine the corresponding value in $\sigma_{\rho}$ (Table 3). We find an increase in variability at the firn-ice transition with increasing mean annual temperature (correlation coefficient of the fit $r=0.822$ ) and increasing accumulation rate (Figure 9a, $r=0.634$, and Figure 9b, $r=0.738$, orange line). This observation supports the assumption of a dependency of density variability at the firn-ice transition on mean annual temperature and on accumulation rate, as suggested by Landais et al. [2006] and Kawamura et al. [2006].

[46] For the surface variability we find a clear negative trend with temperature $(r=-0.35$ in the uppermost layers and $\mathrm{r}=-0.92$ at $6 \mathrm{~m}$ depth) and accumulation rate $(\mathrm{r}=-0.61 /$ -0.44 in the uppermost layers and $-0.73 /-0.86$ at $6 \mathrm{~m}$ depth). The higher the temperature or accumulation rate at a site, the lower the density variability, which is the opposite of the trend of the variability at the firn-ice transition. We first calculate the trend for the whole range of accumulation rates 
Table 3. The Air Isolation Density $\rho_{\text {crit }}$, Calculated Using Equation (4) [Martinerie et al., 1992]; the Corresponding Density Variability $\sigma_{\rho}$; Close-Off Depth (Mean Depth); and the Depth at Which the Air Isolation Density is Reached the First (Top Depth) and Last Time (Bottom Depth) Within the High-Resolution Density Profile

\begin{tabular}{|c|c|c|c|c|c|c|c|}
\hline Campaign/Region & Name & $\begin{array}{c}\rho_{\text {crit }} \\
\left(\mathrm{kg} / \mathrm{m}^{3}\right)\end{array}$ & $\begin{array}{l}\sigma_{\rho}, \rho_{\text {crit }} \\
\left(\mathrm{kg} / \mathrm{m}^{3}\right)\end{array}$ & $\begin{array}{l}\text { Mean Depth, } \\
\rho_{\text {crit }}(\mathrm{m})\end{array}$ & $\begin{array}{c}\text { Top Depth, } \\
\rho_{\text {crit }}(\mathrm{m})\end{array}$ & $\begin{array}{c}\text { Bottom } \\
\text { Depth, } \rho_{\text {crit }}(\mathrm{m})\end{array}$ & $\begin{array}{c}\text { Literature } \\
\text { Depth }^{\mathrm{a}}(\mathrm{m})\end{array}$ \\
\hline \multicolumn{8}{|c|}{ Greenland } \\
\hline NGT & B16 & 819.273 & 12.2627 & 63 & 56 & 69 & $71 / 72(1)$ \\
\hline NGT & B17 & & & & & & \\
\hline NGT & B18 & 820.806 & 12.8078 & 59 & 54 & 66 & \\
\hline NGT & B21 & 820.806 & 12.9072 & 62 & 51 & 72 & \\
\hline NGT & B26 & 820.848 & 13.225 & 69 & 59 & 78 & \\
\hline NGT & B29 & 821.319 & 10.5 & 68 & 53 & 77 & $66 / 67(3)$ \\
\hline \multicolumn{8}{|c|}{ Antarctica } \\
\hline Berkner Island & В 25 & 819.156 & 14.5719 & 56 & 50 & 67 & $60 / 59$ (3) \\
\hline DML & B31 & 826.997 & 10.2713 & 82 & 75 & 86 & \multirow{8}{*}{$74(2)$} \\
\hline DML & B32 & 826.997 & 11.2794 & 86 & 77 & 93 & \\
\hline DML & B33 & & & & & & \\
\hline DML & B36/37 & 827.495 & 8.1154 & 88 & 77 & 98 & \\
\hline Pre-IPICS & B38 & 815.003 & 16.586 & 68 & 56 & 83 & \\
\hline Pre-IPICS & B39 & 814.91 & 17.108 & 58 & 48 & 77 & \\
\hline Pre-IPICS & DML95 & 815.514 & 13.4153 & & & & \\
\hline Pre-IPICS & DML97 & 816.072 & 10.0261 & & & & \\
\hline Dome C & EDC2 & 832.019 & 4.5932 & 99 & 93 & 104 & $98.6(2) / 100(3)$ \\
\hline
\end{tabular}

${ }^{a}$ Measured/modeled mean close-off depths are added from the following references: (1) Schwander et al. [1997] for NGRIP and GISP2 as closest points to B16, (2) Kaspers et al. [2004], and (3) Landais et al. [2006], after models by Arnaud et al. [2000] and Barnola et al. [1991], with NGRIP as the closest point to B29.
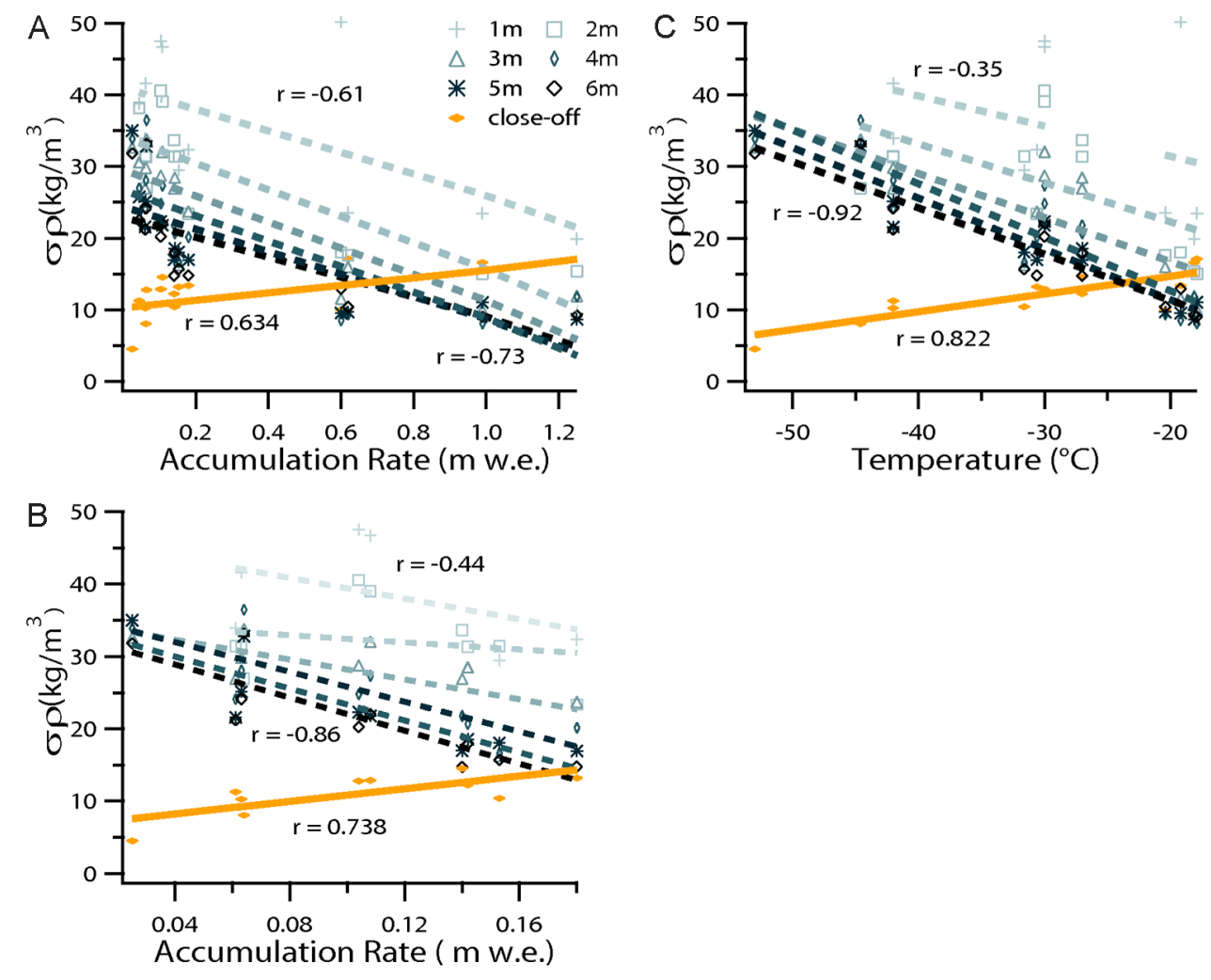

Figure 9. Relationship between $\sigma_{\rho}$ at the surface and at close-off densities. Density variability $\sigma_{\rho}$ at pore close-off densities (orange line), calculated after equation (4), and $\sigma_{\rho}$ at the surface (dashed lines) for depth intervals from 0 (bright grey) to $6 \mathrm{~m}$ (dark grey) depth are shown against increasing (a and $\mathrm{b}$ ) accumulation rate and (c) temperature. In Figure 9a the whole accumulation rate range of all firn cores is plotted. In Figure $9 \mathrm{~b}$ the extremely high accumulation rates of the pre-IPICS cores are excluded and the new fits are calculated. For increasing accumulation rate and mean annual temperature, $\sigma_{\rho}$ at the surface is decreasing, whereas $\sigma_{\rho}$ at the pore close-off is increasing. 
(Figure 9a). In order to make sure that the extremely high accumulation rates of the pre-IPICS cores do not influence the trend, we then exclude the pre-IPICS data and recalculate the trend over the residual range of accumulation rates (Figure 9b). The result is the same in both cases: the density variability at the surface decreases with increasing mean annual temperature and accumulation rate. This decrease indicates a decrease in the number of layers apparent at a certain depth interval with increasing mean annual temperature and accumulation rate. Accordingly low-accumulation sites seem to have more pronounced layering than high-accumulation sites. This finding is in contradiction to the common assumption that low-accumulation sites show only weak or a lack of layering compared to high-accumulation sites [Landais et al., 2006] because of the long exposure to temperature gradients and insulation. Because of the opposite trends of density variability at the surface and at the firn-ice transition with increasing mean annual temperature and accumulation rate (Figure 9) we cannot confirm a direct link of layering at the surface to the extent of a nondiffusive zone near the firn-ice transition. It seems that the surface stratigraphy of polar firn does not directly imply the variability at the firn-ice transition or the thickness of a nondiffusive zone.

[47] Equation (4) estimates the mean density of close-off [Martinerie et al., 1992]. It is assumed that high-density layers approaching close-off density at shallower depths seal off low-density layers from the free atmosphere and thus increase the air volume enclosed in low-density firn. The depth at which this density is approached is crucial for the estimation of the age difference of ice and air. However, the problem of density variability makes the definition of this close-off depth very varied and it is used very differently in the literature [Arnaud et al., 1998, 2000; Landais et al., 2006; Kawamura et al., 2006; Loulergue et al., 2007]. In Table 3 we list the mean density and mean depth at which the air isolation is obtained from equation (4), together with some data from literature. Even though no physical meaning can be extracted from these values, we also show the depth values at which these densities occur for the first and the last time in the high-resolution density profile. Examination of these depths highlights the variability and randomness of the occurrence of critical densities and depth intervals with respect to mean annual temperature, accumulation rate, location or measured density variability.

[48] The question is whether the degree of vertical density variability is the key parameter for the air close-off depth. The horizontal extent of high-density layers at the firn-ice transition (initially low-density layers at the surface) and thus the horizontal variability or the roughness of layers [Martinerie et al., 1992], might play an important role in defining the depth at which firn air is finally sealed off from the pore space above [Freitag et al., 2001]. In that case the parameters to examine more carefully are the conditions at which layers are formed and how layers are extended horizontally in plane. This includes not only the precipitation itself, but the wind and redistribution by wind, which shape the surface, create surface roughness and generate single snow layers with a certain thickness and horizontal continuity. It might be necessary to consider the wind duration, speed and redistribution of snow particles. It might also be important to link the surface variability with the amplitude of temperature variation at a site: a broader temperature range occurring over the year generates a larger difference in the density between single layers. With increasing accumulation rate this impact will cease, thus the degree of variability will decrease, as is suggested by Li and Zwally [2004].

\subsection{Conclusion}

[49] We investigated mean density profiles and density variability obtained from high-resolution firn core measurements. Our results emphasize the need for a physical model for predicting mean density profiles, in order to be able to apply it to a broad range of climate conditions. Furthermore the study of high-resolution density gives detailed insight into the physical process of compaction of stratified firn. In the density profiles investigated we find few or no distinct transitions in the density increase with depth at mean densities of 550,730 and $820-840 \mathrm{~kg} / \mathrm{m}^{3}$, as found elsewhere in the literature.

[50] Density variability as a measure of the layering of polar firn shows a distinct pattern at all sites, excluding local climate conditions as an explanation, and questioning the common idea of homogenous polar firn densification. The more efficient and fast densification of initially low-density layers, overcoming the density of initially high-density layers (crossover), explains the observations of the variability pattern and a switch in correlation of density and electrical conductivity [Gerland et al., 1999] and density and intensity of backscattered light [Hawley and Morris, 2006]. It also implies, that the high-density layers at the firn-ice transition do not originate from high-density layers at the surface. In order to understand the evolution of the density variability and to verify the crossover in density profile of different layers or the impact of impurities and microstructure, the densification process needs to be investigated on a microscale. Therefore a firn core study including high-resolution profiles of chemistry, microstructure and density is strongly needed. Traditional methods to obtain such profiles are very time consuming. But new methods are progressing, enabling a fast and accurate analysis of microstructure [Kipfstuhl et al., 2009]. These techniques will provide more detailed information in the future. In order to link firn layers in their extent, thickness and initial density to the air enclosure process, the lateral extension and continuity of theses layers needs to be considered as well. Therefore knowledge about wind intensity, duration of wind deposition events and the subsequent creation of wind-packed layers on one hand, the extent and distribution of low density layers at the surface, on the other hand, is crucial.

[51] Acknowledgments. We thank the field team of the North Greenland traverse, 1993-1995; Daniel Steinhage and the team of the pre-IPICS traverse, 2006/2007; and Hans Oerter and the team of the DML presite survey, 1997/1998. We are very grateful to Zoe Courville for careful reading of the manuscript. We also thank the two anonymous reviewers for their helpful comments. This work is partly funded by the Deutsche Forschungsgemeinschaft (DFG) grant FR2527/1-1.

\section{References}

Alley, R. B. (1987), Firn densification by grain-boundary sliding: A first model, J. Phys. Colloques, 48, 249-254.

Alley, R. B., J. F. Bolzan, and I. M. Whillans (1982), Polar firn densification and grain growth, Ann. Glaciol., 3, 7-11. 
Anderson, D. L., and C. S. Benson (1962), The densification and diagenesis of snow, in Ice and Snow: Properties, Processes, and Applications, edited by W. D. Kingery, pp. 391-411, MIT Press, Cambridge, Mass.

Arnaud, L., V. Lipenkov, J.-M. Barnola, M. Gay, and P. Duval (1998), Modelling of the densification of polar firn: Characterization of the snow-firn transition, Ann. Glaciol., 26, 39-44.

Arnaud, L., J.-M. Barnola, and P. Duval (2000), Physical modelling of the densification of snow/firn and ice in the upper part of polar ice sheets, in Physics of Ice Core Records, edited by T. Hondoh, pp. 285-305, Hokkaido Univ. Press, Sapporo, Japan.

Barnola, J.-M., P. Pimienta, D. Raynaud, and Y. S. Korotkevich (1991), $\mathrm{CO}_{2}$-climate relationship as deduced from the Vostok ice core: A re-examination based on new measurements and on re-evaluation of the air dating, Tellus, Ser. B, 43, 83-90.

Breton, D. J., G. S. Hamilton, and C. T. Hess (2009), Design, optimazation and calibration of an automated density gauge for firn and ice cores, J. Glaciol., 55, 1092-1100.

Craven, M., and I. Allison (1998), Firnification and the effect of windpacking on Antarctic snow, Ann. Glaciol., 27, 239-245.

Ebinuma, T., and N. Maeno (1987), Particle rearrangement and dislocation creep in a snow-densification process, J. Phys. Colloques, 48, 263-268.

EPICA Community Members (2004), Eight glacial cycles from an Antarctic ice core, Nature, 429, 623-628.

EPICA Community Members (2006), One-to-one coupling of glacial climate variabiltiy in Greenland and Antarctica, Nature, 444, 195-198.

Freitag, J., U. Dobrindt, and S. Kipfstuhl (2001), A new method for predicting transport properties of polar firn with respect to gases on the pore space scale, Ann. Glaciol, 35, 538-544.

Freitag, J., F. Wilhelms, and S. Kipfstuhl (2004), Microstructuredependent densification of polar firn derived from X-ray microtomography, J. Glaciol., 30, 243-250.

Fujita, S., J. Okuyama, A. Hori, and T. Hondoh (2009), Metamorphism of stratified firn at Dome Fuji, Antarctica: A mechanism for local insolation modulation of gas transport conditions during bubble close off, J. Geophys. Res., 114, F03023, doi:10.1029/2008JF001143.

Gerland, S., H. Oerter, J. Kipfstuhl, F. Wilhelms, H. Miller, and W. D. Miners (1999), Density log of a $181 \mathrm{~m}$ long ice core from Berkner Island, Antarctica, Ann. Glaciol., 29, 215-219.

Goujon, C., J.-M. Barnola, and C. Ritz (2003), Modeling the densification of polar firn including heat diffusion: Application to close-off characteristics and gas isotopic fractionation for Antarctica and Greenland sites, J. Geophys. Res., 108(D24), 4792, doi:10.1029/2002JD003319.

Gow, A. J. (1974), Time-temperature dependence of sintering in perennial isothermal snowpacks, IAHS AISH Publ., 114, 25-41.

Hansen, A. C., and R. L. Brown (1986), The granular structure of snow: An internal-state variable approach, J. Glaciol., 32, 434-438.

Hawley, R. L., and E. Morris (2006), Borehole optical stratigraphy and neutron-scattering density measurements at Summit, Greenland, J. Glaciol., $52,491-496$

Herron, M. M., and C. C. Langway (1980), Firn densification: An empirical model, J. Glaciol., 25, 373-385.

Johnson, J. B. (1998), A preliminary numerical investiagtion of the micromechanics of snow compaction, Ann. Glaciol., 26, 51-54.

Kameda, T., H. Shoji, K. Kawada, O. Watanabe, and H. B. Clausen (1994), An empricial relation between overburden pressure and firn density, Ann. Glaciol., 20, 87-94.

Kaspers, K. A., R. S. W. van de Wal, M. R. van den Broeke, J. Schwander, N. P. M. van Lipzig, and C. A. M. Brenninkmeijer (2004), Model calculations of the age of firn air across the Antarctic continent, Atmos. Chem. Phys., 4, 1365-1380.

Kawamura, K., J. P. Severinghaus, S. Ishidoya, S. Sugawara, G. Hashida, H. Motoyama, Y. Fujii, S. Aoki, and T. Nakazawa (2006), Convective mixing of air in firn at four polar sites, Earth Planet. Sci. Lett., 244, 672-682.

Kipfstuhl, S., S. H. Faria, N. Azuma, J. Freitag, I. Hamann, P. Kaufmann, H. Miller, K. Weiler, and F. Wilhelms (2009), Evidence of dynamic recrystallization in polar firn, J. Geophys. Res., 114, B05204, doi:10.1029/2008JB005583.

Landais, A., et al. (2006), Firn $\delta^{15} \mathrm{n}$ in modern polar sites and glacialinterglacial ice: a model-data mismatch during glacial period in Antarctica?, Quat. Sci. Rev., 25, 49-62.
Li, J., and H. J. Zwally (2002), Modeled seasonal variations of firn density induced by steady-state surface air-temperature cycle, Ann. Glaciol., 34 299-302.

Li, J., and H. J. Zwally (2004), Modeling the density variation in the shallow firn layer, Ann. Glaciol., 38, 309-313.

Loulergue, L., F. Parrenin, T. Blunier, J.-M. Barnola, R. Spahni, A. Schilt, G. Raisbeck, and J. Chappellaz (2007), New constrains on the gas age-ice age difference along the epica ice cores, 0-50 kyr, Clim. Past, 3, 527-540. Maeno, N., and T. Ebinuma (1983), Pressure sintering of ice and its implication to the densification of snow at polar glaciers and ice sheets, J. Phys. Chem., 87, 4103-4110.

Martinerie, P., D. Raynaud, D. M. Etheridge, J.-M. Barnola, and D. Mazaudier (1992), Physical and climatic parameters which influence the air content in polar ice, Earth Planet. Sci. Lett., 112, 1-13.

Oerter, H., F. Wilhelms, F. Jung-Rothenhäusler, F. Göktas, H. Miller, W. Graf, and S. Sommer (2000), Accumulation rates in dronning maud land, Antarctica, as revealed by dielectrical-profiling measurements of shallow firn cores, Ann. Glaciol., 30, 27-34.

Palais, J., I. Whillans, and C. Bull (1982), Snow stratigraphy studies at Dome C, East Antarctica: An investigation of depositional and diagenetic processes, Ann. Glaciol., 3, 239-242.

Paterson, W. S. B. (1994), The Physics of Glaciers, 3rd ed., ButterworthHeinemann, Oxford, U. K.

Rotschky, G., W. Rack, W. Dierking, and H. Oerter (2006), Retrieving snowpack properties and accumulation estimates from a combination of SAR and scatterometer measurements, IEEE Trans. Geosci. Remote Sens., 44, 943-956.

Rott, H., K. Sturm, and H. Miller (1993), Active and passive microwave signatures of antarcitc firn by means of field measurements and satellite data, Ann. Glaciol., 17, 337-343.

Salamatin, A. N., and V. Y. Lipenkov (2008), Simple relations for the close-off depth and age in dry-snow densification, Ann. Glaciol., 49, 71-76.

Salamatin, A. N., V. Y. Lipenkov, J. M. Barnola, A. Hori, P. Duvan, and T. Hondoh (2009), Snow/firn densification in polar ice sheets, Physics of Ice Core Records II, edited by T. Hondoh, Hokkaido Univ. Press, Sapporo, Japan, in press.

Schwager, M. (2000), Ice core analysis on the spatial and temporal variability of temperature and precipitation during the Late Holocene in North Greenland, Ber. Polarforsch., 362.

Schwander, J., T. Sowers, J.-M. Barnola, T. Blunier, A. Fuchs, and B. Malaize (1997), Age scale of the air in the Summit ice: Implication for glacial-interglacial temperature change, J. Geophys. Res., 102, 45-47.

Severinghaus, J. P., and M. O. Battle (2006), Fractionation of gases in polar ice during bubble close-off: New constrains from firn air $\mathrm{Ne}, \mathrm{Kr}$ and $\mathrm{Xe}$ observations, Earth Planet. Sci. Lett., 244, 474-500.

Sommer, S., D. Wagenbach, R. Mulvaney, and H. Fischer (2000), Glaciochemical study spanning the past $2 \mathrm{kyr}$ on three ice cores from Dronning Maud Land, Antarctica: 2. Seasonally resolved chemical records, J. Geophys. Res., 105, 29,423-29,433.

Svensson, A., S. W. Nielsen, S. Kipfstuhl, S. J. Johnson, J. P. Steffensen, M. Bigler, U. Ruth, and R. Röthlisberger (2005), Visual stratigraphy of the Northern Greenland Ice Core Project (NorthGRIP) ice core during the last glacial period, J. Geophys. Res., 110, D02108, doi:10.1029/ 2004JD005134.

Wilhelms, F. (1996), Measuring the conductivity and density of ice cores, Ber. Polarforsch., 191.

Wilhelms, F. (2000), Measuring the dieelectric properties of ice cores, Ber. Polarforsch., 367.

Zwally, H. J., and J. Li (2002), Seasonal and interannual variations of firn densification and ice-sheet surface elevation at the Greenland Summit, J. Glaciol., 48, 199-207.

J. Freitag, A. Frenzel, M. W. Hörhold, S. Kipfstuhl, and F. Wilhelms, Alfred Wegener Institute for Polar and Marine Research, Am Handelshafen 12, Bldg. D, Bremerhaven D-27568, Germany. (johannes.freitag@awi.de; andreas. frenzel@awi.de; maria.hoerhold@awi.de; sepp.kipfstuhl@awi.de; frank. wilhelms@awi.de) 